\title{
Online Education: Challenges and Opportunities for Developing Key Competencies of the 21st Century During the COVID-19 Pandemic
}

\author{
Pesha A.V. ${ }^{1 *}$ Kamarova T.A. ${ }^{1}$ \\ ${ }^{1}$ Ural State University of economics, Yekaterinburg, 620144, Russia, myrabota2011@gmail.com \\ *Corresponding author. Email: myrabota2011@gmail.com
}

\begin{abstract}
This paper presents the results of the study of the difficulties and opportunities of online education. COVID19 has accelerated technological advances in higher education and has opened up a number of challenges. The solution of these problems is necessary for the effective development of key competencies of the XXI in the online format. The authors present the results of a survey of students from 28 universities of the Russian Federation about the difficulties and opportunities of the online format learning. The results of the study show a high level of respondents' dissatisfaction with the quality of online educational services. In addition, a third of the respondents note the technological personal unpreparedness for the transition of education to the online format. Regarding the possibilities of supra-professional competencies, it can be noted that the forced transition to the online learning mode contributed to the development of digital competencies and somewhat reduced the opportunities for the development of social and emotional competencies. The paper notes that there are pros and cons of online learning and the great prospects of education in a digital educational environment.
\end{abstract}

Keywords: higher education, online education, supra-professional competencies, key competencies, digital

educational environment

\section{INTRODUCTION}

Digitalization opens up new horizons for large-scale changes in the field of higher education. This happens both from the point of view of the possibilities for improving the educational system, and from the point of view of the need for a fundamental modernization of business processes and organizational structure, as well as the development of teachers' potential $[1 ; 2]$. The higher education system has changed dramatically over the past decade. Education has become accessible and thanks to distance forms it has become possible to access educational content anywhere in the world.

In addition, the transformational processes taking place in the labour market contribute to large-scale changes in higher education. To ensure the sustainability and competitiveness of their businesses, enterprises and employers make more and more serious demands on the development of the competencies of specialists trained by the university [3; 4]. More and more professions appear on the labour market associated with a high level of development of digital competencies: web designers, data scientists, information security specialists and others. Nevertheless, a high level of development of digital competencies is currently required to ensure sustainable personal development and competitiveness of the company for specialists in other fields. This fact is confirmed by a large number of studies in the field of digital competencies and the labour market [e.g. 5; 6]. Rakesh Kochhar (2020) notes the high demand for the development of programming and data analysis skills in 163 professions out of 967 studied [5].

In addition to a high level of development of digital competencies, a professional in the 21 st century needs a high level of development of a wider range of nonprofessional (supra-professional, key) competencies [710]. By supra-professional competencies, we mean a wide range of skills and behaviour patterns, characteristics of interpersonal relationships and personality traits that allow a person to quickly navigate and adapt to the tasks and challenges of the environment, build relationships and establish contacts, show high work efficiency and achieve set goals and objectives [11]. In the structure of supraprofessional competencies, we distinguish 4 clusters: socio-emotional competences, cognitive competencies, communicative and digital competencies. The key point is the variability of the set of supra-professional competencies for different professions. So, for example, digital competencies for an IT specialist will be professional, while for an HR manager they will be supraprofessional.

In addition to the above factors influencing the need to transform approaches to the implementation of educational standards of higher education, it is necessary to note the 
emerging global threat, which has made a significant contribution to the process of changes.

\subsection{The main problems of higher education related to the pandemic}

COVID-19 destroys the way of life we are used to, threatening not only human health, but also leading to serious disruptions to socio-political and economic life. The challenge of 2020, which swept the whole world, dictated new living conditions to specialists in many fields of activity, and not everyone was equally ready for it. The crisis has had an impact on the work of university teachers and on education, the impact of the pandemic is unprecedented, and we all accept it in different ways. Conducting classes at the university was forced to completely switch to digital educational platforms as the main environment for the professional habitat of teachers. The key question we are facing now is how effective will this transition be? An urgent change of methodological tools leads to the fact that all materials are being finalized and tested already in the educational process. Are teachers ready for a distance learning format? How to remotely develop and assess the level of development of students' competencies? What innovative solutions and technological changes must now be made by the government and university leadership as an effective response to the global challenge? What problems did teachers and students face and how to counter the negative impact of COVID-19? Issues that have become the subject of discussion among the stakeholders of the educational process and scientists $[12 ; 13]$.

\subsection{Subject and objectives of study}

The object of research in this paper is the development of supra-professional competencies of university students to ensure the competitiveness of an individual, organization and the State.

The subject of the research is the development of supraprofessional competencies of students during a pandemic and a complete transition to the online learning format.

The main goal of this work is to present the results of an empirical study of the impact of the implementation of academic disciplines in the online format on the development of supra-professional competencies of students.

Research methods: the research is based on modern concepts of science and practice of education, the concept of technological didactics, as well as labour economics. In particular, the authors applied the methods of content analysis and data interpretation in their work, an online survey of students about their satisfaction with the educational process during the pandemic.

\section{RESULTS}

\subsection{Method description}

Online survey of students. The survey was conducted anonymously. A mailing list with an invitation to take part in the survey was sent to students via ICT. The main tool for attracting participants to the research is networking. After clicking on the link, the participants received instructions for taking the survey. No personal data was collected from the participants. There were 5 key questions in the survey:

- What problems of working in a digital educational environment have you faced?

- What, in your opinion, are the prospects for learning in a digital educational environment?

- How ready are you for learning using digital technologies?

- What, in your opinion, are the opportunities for the development of socio-emotional, cognitive, communicative and digital competencies in online learning?

- An open question about the opinion of students regarding learning using digital educational resources during a pandemic.

\subsection{Participants}

The survey involved 249 students from 28 Russian universities. $18.47 \%$ are distance learning students, $81.53 \%$ are full-time students. $3.2 \%$ are graduate students, 96.8\% are bachelor students. Participants' training cities: Yekaterinburg (75.6\%), Moscow (10.2\%), Saint Petersburg (7.75\%), Omsk (3.2\%), Krasnodar (1.65\%), Volgograd $(0,4 \%)$, Nizhnevartovsk $(0.4 \%)$, Lesnoy $(0.4 \%)$, Nizhny Tagil $(0.4 \%)$.

Most of the respondent's study in 1-3 courses (64 1st year students, 106 2nd year students, 51 3rd year students). The choice of the target audience is justified by the greatest inclusion of these courses of students in training through digital educational technologies. 4 th and 5 th year students are less involved in the survey, since during the period of the study and at the time of the start of quarantine measures, they were undergoing pre-diploma practice at enterprises (17 and 3 people, respectively). The survey also involved 8 people studying the master's degree.

\subsection{Online education and development of students' competencies during a pandemic}

The first question that was asked to the students was of a general nature and immersed them in the research topic: "Has the quality of education at the university changed in your opinion during the pandemic?" The votes of the 
respondents were distributed approximately equally between the options: nothing changed (26\%), changed for the worse, insignificantly $(25.2 \%)$ and changed for the worse and significantly (24\%) (Figure 1). In general, the respondents note the negative changes that have occurred in the educational process during the pandemic. Among the answers "other", students also note negative consequences: it is impossible to cover debts, the comfort of learning in the classroom and a decrease in the quality of services provided. If we analyze the difference in answers to the question of full-time and part-time students, then it is significant. Part-time students do not feel a significant difference in education, which occurred during the pandemic ( $46.9 \%$ of respondents), this is due to the specifics of distance education. Distance learning students continue, as in previous sessions, to carry out tests, the only change is interaction with the teacher not live, but through digital technologies.

The deterioration in the quality of education, which occurred in connection with the transition to a digital educational environment, was noted in the answers by more than half of the respondents of full-time education $(56.4 \%)$ and almost a third of students of distance education $(28.6 \%)$. The following research questions will help to understand more deeply the reasons for such answers to the question.

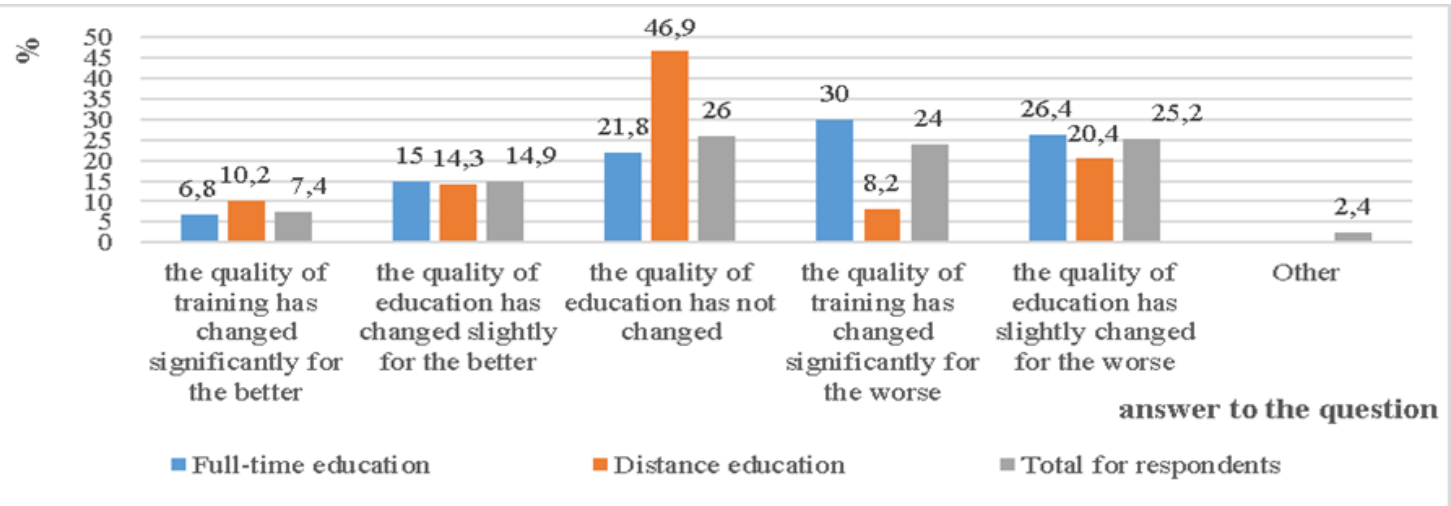

Figure 1 Results of respondents' answers to 1 question about the quality of education at the university (in $\%$ of the total number of responses)

The next question we asked the respondents was what problems they faced in working in the digital educational environment during the pandemic? The answers of the respondents across the entire sample are presented in Figure 2. The main problem noted by the majority of respondents $(61.6 \%)$ is related to the lack of interaction with the teacher and classmates. Communication in the Digital educational environment is indirect and group interaction at this stage in the conditions offered to teachers is hardly possible. Unfortunately, there is a great technological gap between the existing technologies of interaction in the World and those technologies that are used in higher education. The digital divide in education, which has now become more relevant than ever, is being studied by scientists before, but we were not ready for it enough.

The difference in accessibility to digital technologies among students is large, part of students dropped out of the educational process due to lack of technical support, this problem was also noted by respondents $(28.9 \%)$. Among other answers, students note the lack of "live communication"; lack of video conferencing and interaction via chat in electronic educational resources (EER); self-study, instead of pairs; constant work in front of the computer. The absence of problems was noted by 2 respondents out of 249 survey participants. There were no significant differences in the opinions of full-time and distance learning students on this issue.

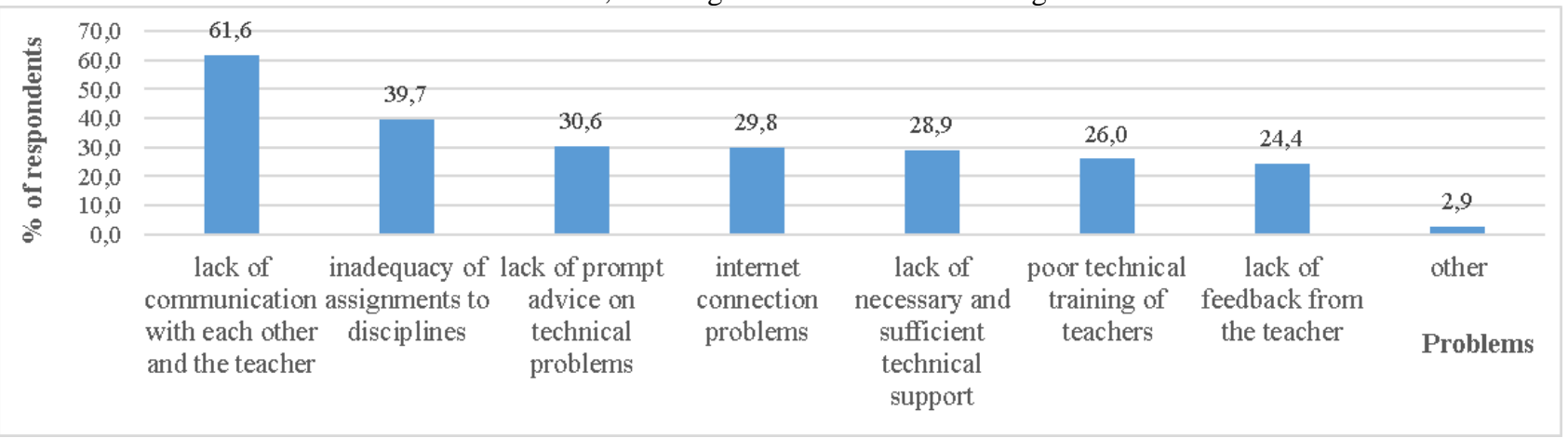

Figure 2 Problems faced by students while working in the digital educational environment during a pandemic 
With the next two choice questions, we asked students about the prospects for online learning and their personal readiness for this form of higher education.

Most of the students see ample opportunities and prospects for learning using digital technologies, provided they are combined with direct interaction in classrooms. The need for communication with each other and with the teacher, noted in the answers to the second question, is also confirmed in the vision of the prospects for education in the digital environment.

$29.7 \%$ of students surveyed suggest that learning in a digital educational environment will be cancelled along with the lifting of quarantine measures caused by COVID19. In addition, $1.3 \%$ of respondents noted that distance learning reduces the quality of knowledge transfer, there are prospects only if universities are interested in the development of a digital educational environment to the level of the ability to transfer high-quality knowledge, skills and abilities that are adequate to the demands of the external environment.

Such answers demonstrate that in fact one third of the respondents do not see the prospects for digital technologies in education. This thesis is undoubtedly erroneous, the development of the economy and technology just testifies to the opposite and, in our opinion, most of the educational process will somehow go into the digital environment. The traditional educational approach is replaced by the philosophy of Smart Education (smart education) using digital technologies [14; 15].

Digital competencies and digital skills are one of the key supra-professional competencies required for success in the digital and knowledge economy, which is confirmed by the results of numerous studies of skills and competencies of the 21 st century [16]. To work in a digital educational environment, both teachers, the entire staff serving the educational process and students should have a high level of development of digital competencies. By the question of the readiness of students to switch to a learning format using digital educational technologies, we learned the motivation and attitude of students, personal attitude and desire to develop their digital competencies and skills. A fifth of the respondents $(20.7 \%)$ say they are fully ready to learn using digital educational technologies, while most of the respondents note that they are ready in the 50/50 format using traditional educational technologies in the classroom. A quarter of respondents are sceptical about learning using digital technologies $(25.3 \%)$; here we can see some correlation with respondents' answers about the lack of prospects for digital education. The answers of a quarter of the students surveyed have a clearly negative connotation of mood regarding the current educational conditions. In addition, $6.3 \%$ of respondents noted dissatisfaction with the quality of education before the pandemic, conducted in the traditional format, and its even greater decline in current conditions.

The respondents' answers about the possibilities of developing supra-professional competencies in online education by cluster are presented in Figure 3. A 5-point Likert scale was used for the assessment (1 - there are no opportunities, 3 - there are opportunities, but they are not enough, 5 - there is a wide range of opportunities).

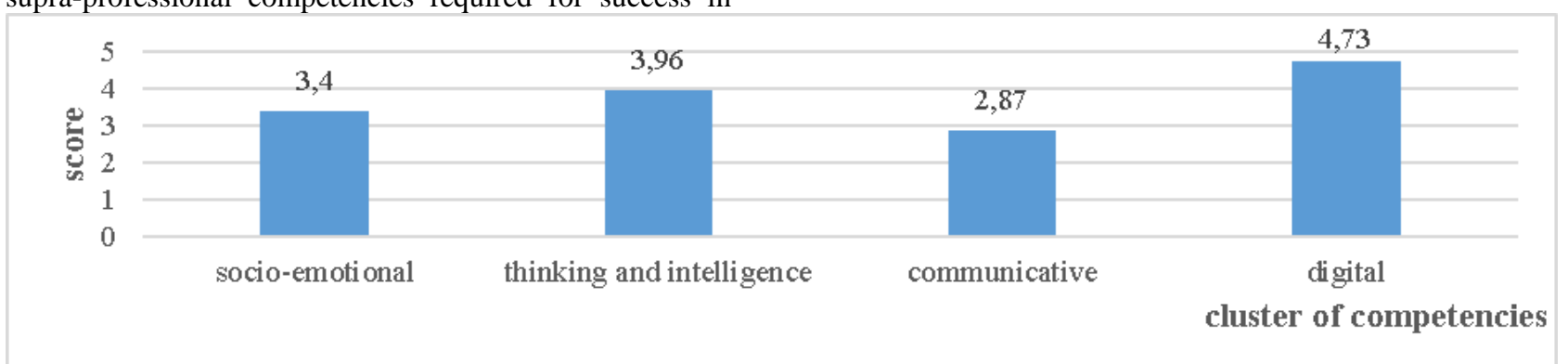

Figure 3 Opportunities for the development of supra-professional competencies in online education

Suddenly, the difficulties that arose effectively neutralized the possibilities of conducting business games, group discussions, group solution of cases and other team types of work during training due to the digital unavailability of teachers, students and universities. Group forms of training are necessary for the development of such important supra-professional competencies. Such competencies as "interacting with people", "negotiating" and others, and skills such as teamwork and problem solving, which are applicable and useful for most areas of employment. These competencies are very difficult to develop individually, and after all, it is these skills and competencies based on the results of a large number of studies that are key for specialists of the future $[5 ; 17]$.

Despite the fact that digital technologies open up new opportunities for collaboration, the development of competencies in the field of communication and interaction with people with the existing set of digital solutions available to the educational environment is more effective in direct communication in the classroom. Students are happy to take part in online quests, quizzes and develop chat bots, at the same time, business games in the classroom can develop a much wider range of skills necessary for the success of a specialist of the future. In addition, the development of online quests, quizzes and other interactive learning tools is currently a proactive work of teachers based on self-motivation and love for the profession.

Of greatest interest from the point of view of collecting students' opinions on the organization of education in a digital educational environment are the answers of respondents to an extreme, open question. The question 
was optional. Out of 249 respondents, 110 (44.2\%) people presented their opinion describing in a few words their view of learning using digital educational resources during a pandemic. The opinions of students on the organization of the educational process in the digital educational environment were negative in $54 \%$ of cases. Most of the positive assessments of the situation were given by correspondence students (74\%). Extramural students noted that for them there were no significant changes with the transition to training in a digital educational environment. Thus, 5 respondents (2\% of the total) noted that the transition to distance education is a forced measure that allows not to stop the educational process and the transfer of knowledge. At the same time, 2 survey participants noted that a much more rational solution could be to shift school time to summer months, instead of holidays.

Students in their comments often noted the discrepancy between the quality of full-time education, its cost and the student's expectations from learning $(11.6 \%$ of respondents).

Students note that teachers use different educational platforms, not always only those provided by the university, due to their inefficiency. On the one hand, this allows you to receive explanations and feedback from the teacher, on the other hand, it makes it necessary to constantly switch from one resource to another, which is not technically comfortable.

Of the advantages, students note the ability to combine study with work and saving time on the road. Also, students note that digital educational technologies add variety to the educational process and make it more interesting.

Proactive students in the comments note that they compensate for the lack of quality of education at the university by training on open educational resources, which, during a pandemic, implement part of the programs free of charge.

\section{CONCLUSION}

Currently, the requirements for candidates in the digital labour market are changing significantly. The task of the university is to create conditions for comfortable and productive work, for the growth and development of the student during distance learning. So, until recently, when searching for personnel, the main skills were "Hard Skills", professional skills and competencies that can be taught and measured, necessary for an employee to work in a specific profession and position. In modern society, the most important are supra-professional, soft skills and competencies, which are important in every profession and depend on the personality of the employee: communicative, social, cognitive and digital competencies. In the remote interaction of a teacher and a student, not only the key tools that digital technologies are becoming are changing, but also communication. The process of management (planning, organization, motivation and control) of students' activities in remote learning is also subject to changes. In addition, team interaction is also changing, which also goes into a virtual format, which is now possible to support with the help of a large number of online services.

In the current conditions dictated by the education system of the global COVID-19 pandemic, teachers did not have time to develop digital tools that would fully develop both professional and supra-professional competencies. The quality of the educational process could have decreased, and the development of digital competencies could not have been enough for any of the active participants in educational activities that switched to a digital environment.

How ready was the higher education system and how satisfied were the students with the changes in the educational process during the forced transition to learning in a digital educational environment? In the empirical part of the study, we analysed the problems and opportunities that arose in the educational process of universities during the COVID-19 pandemic, having studied the opinions of students. There are pros and cons to learning with digital education technology. One thing is certain, technology is the future. Teachers and students realized the need to change their own competencies when we were faced with the situation of a sudden transition of the educational process into a digital environment. The field of higher education has realized the need to restructure the educational process, change the attitude and motivation of students and teachers.

\section{ACKNOWLEDGMENT}

The reported study was funded by RFBR, project number 19-29-07435

\section{REFERENCES}

[1]Bridgstock, R. The university and the knowledge network: A new educational model for twenty-first century learning and employability. In M. Tomlinson \& L.Holmes (eds) Graduate employability in context (2017). (pp. 339-358). London: Palgrave Macmillan. DOI: https://doi.org/10.1057/978-1-137-57168-7_16

[2]Popenici, S. A., \& Kerr, S. Exploring the impact of artificial intelligence on teaching and learning in higher education. Research and Practice in Technology Enhanced Learning, 12(1), (2017), 22. DOI: https://doi.org/10.1186/s41039-017-0062-8

[3]Becker, S. O., Muendler, M. A. Trade and tasks: an exploration over three decades in Germany. Economic Policy. (2015), 30 (84), pp. 589-641. DOI: https://doi.org/10.1093/EPOLIC/EIV014

[4]Smidt, W. Big Five personality traits as predictors of the academic success of university and college students in early childhood education. Journal of Education for 
Teaching. (2015), 41 (4), pp. 385-403. DOI: https://doi.org/10.1080/02607476.2015.1080419

[5]Kochhar, R. New, emerging jobs and the green economy are boosting demand for analytical skills, 2020. URL: https://pewrsr.ch/2Un8CmG.

[6]Jandrić, M \& Ranđelović S. Adaptability of the workforce in Europe-changing skills in the digital era. Zbornik radova Ekonomskog fakulteta u Rijeci: časopis za ekonomsku teoriju i praksu 36.2 (2018): 757-776. DOI: https://doi.org/10.18045/zbefri.2018.2.757

[7]Bridgstock, R., \& Jackson, D. Strategic institutional approaches to graduate employability: navigating meanings, measurements and what really matters. Journal of Higher Education Policy and Management, 41(5), (2019), pp. 468-484. DOI: https://doi.org/10,1080/1360080X.2019.1646378

[8]Sahin, A. The Role of Interdisciplinary ProjectBased Learning. in Integrated STEM Education. A. Sahin \& Margaret J. M-S. (eds). In STEM Education 2.0 (2019), pp. 93-103. Brill Sense. DOI: https://doi.org/10.1163/9789004405400_006

[9]Succi, C., \& Canovi, M. (2019). Soft skills to enhance graduate employability: comparing students and employers' perceptions. Studies in Higher Education, March, 1-14. DOI: https://doi.org/10.1080/03075079.2019.1585420

[10]Wiek, A., Withycombe, L. \& Redman, C.L. Key competencies in sustainability: a reference framework for academic program development. Sustain Sci 6, (2011), pp. 203-218. DOI: https://doi.org/10.1007/s11625-011-0132-6

[11]Pesha, A.V. Assessment center in the study of the level of development of supra-professional competencies of students in the direction of "HRmanagement". in EDULEARN20 Proceedings 12th International Conference on Education and New Learning Technologies. (2020) pp. 1259-1266. DOI: https://doi.org/10.21125/edulearn.2020.0417

[12]Fuller, R., Joynes, V., Cooper, J., Boursicot, K., \& Roberts, T. Could COVID-19 be our 'There is no alternative'(TINA) opportunity to enhance assessment? Medical teacher 42.7 (2020): pp. 781-786. DOI: https://doi.org/10.1080/0142159X.2020.1779206

[13]Garcia-Penalvo, F. J., Corell, A, Abella-Garcia, V., Grande, M. La evaluación online en la educación superior en tiempos de la COVID-19. (2020), 26 p. DOI: https://doi.org/10.14201/eks.23013
[14]Visvizi, A., Lytras, M. D., Daniela, L. (Re) defining smart education: Towards dynamic education and information systems for innovation networks //Enhancing knowledge discovery and innovation in the digital era. IGI Global, 2018. pp. 1-12. DOI: https://doi.org/10.4018/978-1-5225-4191-2.ch001

[15]Zhu, Z. T., Yu, M. H., Riezebos, P. A research framework of smart education. Smart learning environments. (2016), 3(1), p. 4. DOI: https://doi.org/10.1186/s40561-016-0026-2

[16]Wang, Y., Lavonen, J., Tirri, K. Aims for learning 21 st century competencies in national primary science curricula in China and Finland. EURASIA Journal of Mathematics, Science and Technology Education. (2018), 14 (6), pp. 2081-2095. DOI: https://doi.org/10.29333/ejmste /86363

[17]Jackson, D. Re-conceptualising graduate employability: The importance of pre-professional identity.Higher Education Research \& Development. (2016), 35 (5), pp. 925-939. DOI: https://doi.org/10.1080/07294360.2016.1139551 